\title{
Modelling the Volatility of Stock Indices and Foreign Exchange Rates in BRICS : Empirical Evidence from GARCH Models
}

\author{
Zacharias Bragoudakis ${ }^{1, *}$ and Rafail Voulgarakis ${ }^{2}$ \\ ${ }^{1}$ Bank of Greece. \\ ${ }^{2}$ University of Piraeus.
}

\begin{abstract}
This paper models and estimates the volatility of stock indices and foreign exchange rates in BRICS, using univariate GARCH models. The data cover the period 13/05/1999-22/11/2018. The conditional variance is modeled with a GARCH $(1,1)$, IGARCH, EGARCH and GJR-GARCH. The results suggest that the GJR-GARCH model outperforms the other GARCH family models and provides a clear direction on how to critically estimate volatility. Our findings also indicate the existence of persistency in the indices returns and in the forex rates returns. Moreover, both financial assets have a leverage effect, while the impact of financial shocks is asymmetric.
\end{abstract}

Keywords: Volatility, GARCH, BRICS, Financial Markets.

JEL classification: C5, C13, C53, C55, C58.

\section{INTRODUCTION}

Financial time series are characterized by heteroscedasticity. This phenomenon depicts that a time series with returns is highly affected by the impact of news in the financial markets. There have been many efforts to model current and future volatility. GARCH type models are a useful tool to capture time varying volatility. The researcher can manipulate latency in financial data either by inferencing e.g. using an ARCH model or by using option data to calculate the implied volatility. In the matter of implied volatility, research has focused on option pricing and hedging as in the celebrated Black and Scholes model (became known in 1973). The model assumes constant volatility, a feature which does not respond to what is observed in the data. Despite its drawbacks, the model remains a useful technique to model volatility. In this study, we use univariate GARCH models with daily closing pricings of the stock indices and forex markets. By doing that, we fill the gap in the literature on modelling volatility of two financial assets through extended time period covering the 2008 financial crisis and its aftermath.

The purpose of this paper is to examine the function and the accuracy of GARCH volatility models, as well as, their forecasting power in BRICS countries (Brazil, Russia, India, China, and South Africa). Furthermore, our second goal is to provide a clear picture of volatility in the five basic emerging economies by including periods of economic prosperity and severe economic distress, and by giving useful insight to related stakeholders e.g. policymakers, regulators. To the best of our knowledge, there are no studies in the literature that

*Address correspondence to this author at Economic Analysis and Research Department, Head of Econometric Forecasting Section, 21, E. Venizelos Avenue, GR-102 50 Athens, Bank of Greece; Tel: +30210-3203605; Fax: +30210-3233025; E-mail: zbragoudakis@bankofgreece.gr investigate the dynamics of financial assets of BRICS in such a very long period.

The present study aims to complement the literature in several ways. First, we focus our attention on BRICS as a whole, considering that we have a larger set of data from 13/5/1999 to $22 / 11 / 2018$, including all major events and ups and down of the world economy, in contrast to the current literature. Second, we compare a set of univariate GARCH models, both from a symmetric and an asymmetric perspective.

The remaining parts of the paper are organized as follows: Section 2 provides the literature review while Section 3 describes the methodology that was used. On Section 4 there is a presentation of the data and in Section 5 we present and discuss the empirical results. In the last section 6 we provide some conclusions.

\section{LITERATURE REVIEW}

There are many studies that use GARCH type models for modelling volatility with various time ranges. Our basic goal is to investigate volatility of the financial assets and to that end, we examine previous studies that use similar approaches to BRICS.

The autoregressive conditional heteroscedasticity model (Engle, 1982) and its generalized version (Bollerslev, 1986) focus on capturing efficiently volatility clustering. Financial econometrics assume either homoscedasticity (when the variance of the error terms is constant over time) or heteroscedasticity (when the constant variance assumption is violated). However, in most financial times series the researcher can detect high levels of volatility followed by periods of low volatility (Mandelbrot, 1963 and Fama, 1965). Due to the presence of skewness and asymmetry, we should consider using either the GJR-GARCH model by Glosten, Jagannathan and Runkle (1993) or EGARCH model by Nelson (1991). In most of the 
cases, the assumption of homoscedasticity is violated so it is necessary to examine the conditional variance and not the unconditional ( long run forecast of the variance and can be treated as constant). Officer (1973) uses standard deviations of returns for estimating volatility, while Merton (1973), states that an asset price follows a diffusion with volatility being constant, as a Geometric Brownian Motion. Because most of the related literature assume that volatility is constant, there is a need for a parametric model. Secondly, to our best knowledge, literature lacks of a clear comparison of the most basic volatility models, in forex markets and stock indices of BRICS. Considering that we have a large dataset of various periods gives us the edge to acquire a clear understanding of volatility in BRICS and gives us ground for a more accurate estimation and forecast.

Stock markets and foreign exchange rates are perceived as some of the most volatile assets. In addition, the essence of volatility is highly related to risk. First Hsieh (1988) by using an $\mathrm{ARCH}$ model to observe volatility in five exchange rates finds that there is a nonlinear relation correlation on the data, thus he suggests the use of GARCH. In an attempt to better understand risk and volatility in financial markets, the use of GARCH type models is an indicative solution (So and $\mathrm{Yu}$, 2006). Tabajara et al,. (2008) use the $\operatorname{GARCH}(1.1)$, EGARCH, TARCH and find that BRICS shows less persistence to volatility shocks, less asymmetry, and more reaction of volatility to market changes. Bouri et al., (2018) explain the volatility in energy/commodities markets of BRICS to predict the sovereign risk in the quantiles. By employing an EGARCH they find the persistency of leverage effect, proving that a negative shock has far greater ramification on the market than a positive news shock.

Dritsaki (2017) uses mainly GARCH(1,1) and $\operatorname{EGARCH}(1,1)$ to capture the symmetric volatility and the leverage effect and suggests the use of static procedure for better forecasting. On the same side, Ewing et al. (2002) underlines that by studying the volatility, patterns can be found that are useful for every participant in financial markets. Although they use a multivariate GARCH to study the spillover effects, they agree that the GARCH model is the most popular and robust way to model volatility and to generally deal with high frequency data.

The implications of volatility as macroeconomic factor is described by Waqas, Hashmi and Nazir (2015). The study uses data from 4 south Asian countries, which are incorporated into a GARCH (1,1 that yields faster responses. The outcome of the study reveals that the volatility related to interest rates plays a significant role on investment portfolios. Furthermore, Glosten, Jagannathan and Runkle (1993) add a short-term nominal interest rate to a great variety of GARCH type models and conclude that their addition has a positive effect on volatility in stock market returns.

The standard GARCH is unable to capture the variation in volatility. Goyal (2000) shows that GARCH models perform better on forecasting volatility as they lie in the confidence interval of the proxy of the actual volatility. Furthermore, Chen and Shen (2004), in their study of the Asian crisis, report that volatility models are also used to measure stock synchronicity. Stock synchronicity is a useful signal to measure asset allocation in stock markets. These models can be used to measure normal and extreme activity in financial markets (Gao et al., 2018). Labuschagne et al., (2015), state that volatility models are useful to clustering the data about volatility skew across different stocks indices. They compare a Risk Neutral Historic Distribution, an EGARCH and GJR GARCH model for extracting the volatility skews for BRICS stock exchanges indices. To the same direction, Lin (2018) in his testing of the SSE Composite Index using various types of GARCH models, verifies that the Index shows time carrying and clustering, along with ARCH and GARCH effects. He also compares GARCH, TARCH and EGARCH $(1,1)$ and he concludes that the EGARCH $(1,1)$ performs better than the others.

Choudhry and Wu (2008) compare four GARCH models for forecasting. They find that among the GARCH models, GJR and EGARCH models outperform the others, while, Liu and Hung (2010) compare GARCH models on forecasting volatility in S\&P 100. They use among others, the GJR-GARCH and the EGARCH and they verify that these two models produce the most accurate forecasts. They conclude that it is better to model asymmetric effects than specifying the error distribution. But if asymmetries are ignored, then GARCH models with a normal distribution are more parsimonious, thus more preferable to others.

Rahman and Alam (2012) provide evidence that the EGARCH along with the TARCH model outperform all the other models and recommended them as means to capture volatility in foreign exchange rates. Finally, Epaphra (2017) uses nonlinear series for the forecasting of daily data on the exchange rate of Tanzania (TZS/USD) from 4 January 2009 until 27 July 2015. By using the symmetric GARCH model and the asymmetric EGARCH model, he concludes that the symmetric GARCH model gives better results on forecasting, but the asymmetric EGARCH presents leverage effect implying a higher next period conditional variance than negative shocks of the same sign.

Alberg et al. (2008) on studying the Tel Aviv Stock Exchange (TASE), they use mainly asymmetric GARCH models and state that these models forecast better the leverage effect and asymmetric volatility. Especially the EGARCH with a skewed Student $-\mathrm{t}$ distribution provide the best forecast on the TASE index.

\section{MODELLING}

\subsection{Methodology}

To begin with, Engle (1982) proposed a model called Autoregressive Heteroscedastic (ARCH) to explain and capture the volatility structuring. Furthermore, the variance of the residuals at time $t$ depends on the square error of the past $(t-1, t-$ 2 ). So, it is needed to model the mean and the variance of the series.

A common issue with volatility is that it cannot be observed. The daily volatility is not directly observable because there is intraday volatility and overnight volatility. Regarding option markets, there is also the implied volatility, which might be different than the actual volatility. General Autoregressive Heteroscedastic (GARCH) models tend to capture more precisely the implied volatility. GARCH model has several advantages. First, it captures volatility clustering (high volatility for some time periods is followed from time periods of lower volatility. Apart from that time is continuous time, volatility 
jumps are rare. Volatility also is characterized for its leverage effect. Volatility reacts differently to high prices and to lower prices. Most financial time series depict fat-tails and satisfy the long memory property. $1 \mathrm{We}$ estimate the $\mathrm{ARCH}$ and GARCH models by using the maximum likelihood approach. The approach is useful as we can estimate the mean and the variance simultaneously. Thus, the investor can except for the return on investments, to minimize the investment risk. By modifying the mean equation and introducing the conditional variance to consider the risk (Gujarati, 2011).

To model volatility we use the most common univariate models: The General Autoregressive Conditional Heteroscedasticity Model GARCH $(1,1)$, the Integrated GARCH, the Exponential GARCH, GJR-GARCH (Glosten-JagannathanRunkle GARCH). For volatility estimation we use quasi maximum likelihood estimation, while all GARCH processes are identically and independent distributed with a zero mean and unit variance (strong GARCH). By lessening the assumptions, we don't use a unconditional correlation, which is a weak GARCH. By detecting patterns they can be exploited for an ex ante forecasting (Herwartz, 2018).

There should be a complete reference to the leverage effect that characterize financial returns. To capture the leverage effect a useful way is to plot the daily log returns and the recursive standard deviation of returns for each variable (Degiannakis and Xekalaki, 1999). After that, we have to test for stationarity. For that purpose, we use the Kwiatkowski-PhillipsSchmidt-Shin (KPSS) test. The time series is the sum of deterministic trend, random walk and stationary error. To estimate the volatility in the volatility models, daily log returns are extracted for each time series to make the data more linear .We use return data and generate them by dividing the price at time $\mathrm{t}\left(p_{t}\right)$ by the preceding price $\left(p_{t-1}\right)$. Then we take the natural logarithm, which is the logarithmic first difference:

$l r_{t}=\ln \left(P_{t} / P_{t-1}\right)$

where $r_{t}$ is the daily return, $p_{t}$ and $p_{t-1}$ denote the index price or the forex rate for the day $t$ and $t-1$, respectively.

After that the Augmented Dickey Fuller test is used to test for stationarity. The null hypothesis states that a unit root exists, while the alternative hypothesis exists for stationarity. The models' parameters are estimated by using the maximum likelihood estimator. Then follows the fitting of the models. The KPSS test is being used to fit an ARMA model to construct the mean equation. After that, the most appropriate model is selected in relation to the maximum log likelihood value. There are also taken into consideration two basic criteria for selecting the best model, Akaike Information Criterion (AIC) and Bayesian Information Criterion (BIC).

Firstly we define the mean equation of a univariate time series:

$x_{t}=E\left(x_{t} \mid F_{t-1}\right)+\varepsilon_{t}$

where $\mathrm{E}(\cdot \cdot)$ denotes the conditional expectation operator, Ft -1 the information set at time $\mathrm{t}-1$, and $e_{t}$ the innovations of the time series. After that, we proceed with fitting an ARMA model to estimate the most appropriate mean equation for each model. For each model we use a 1,1 form. Then we move to a 5-step forecasting and then the sigma and fitted forecast. Lastly, we provide the forecast evaluation to estimate the correctness of the forecasts.

\subsubsection{The Standardized GARCH Model}

Volatility is characterized by persistency or they have long memory. Financial time series can have autocorrelations that are statistically significant for many lags. But on stationary ARCH or GARCH models the memory decays exponentially. That's why the financial literature moves from Engle (1982) to Bollerslev (1986), to include the volatility persistency as realistically as possible.

The model differs to the ARCH model in that it incorporates squared conditional variance terms as additional explanatory variables. This allows the conditional variance to follow an ARMA process. The residuals are written as $h_{t}$, with $v_{t}$ and the method of estimation is the maximum likelihood (MLE).

The ARCH model is derived from a simple regression model, which has a normal distributed error term with zero mean and standard deviation of $\sigma$, it follows:

$y_{t}=a+b x_{t}+u_{t}$

$u_{t}=y_{t}-a-b x_{t}$

$f(u)=\frac{1}{\sigma \sqrt{2 \pi}} e^{-1 / 2\left(\frac{u}{\sigma}\right)^{2}}$

The probability density can then be determined by substituting in the ut expression. The log-likelihood function will then be given by:

$\log L=n \log \left(\frac{1}{\sigma \sqrt{2 \pi}}\right)-\frac{1}{2 \sigma^{2}}\left[\left(y_{1}-a-\beta \chi_{1}\right)^{2}+\cdots\left(y_{n}-\right.\right.$ $\left.\left.a-\beta \chi_{n}\right)^{2}\right]$

Then the values of $\alpha$ and $\beta$ that maximise this function are the same as those obtained by OLS.

\subsubsection{The EGARCH Model}

The parameter $\mathrm{g}$ is interpreted as a leverage effect and it counts for any asymmetry on the volatility response to negative and positive shocks. If $g$ is positive, the past negative shocks have a larger impact on conditional variance than the positive shocks.

The GARCH model can be extended to include any number of lags on the squared error term and conditional variance term. The GARCH(p,q) model has $p$ lags on the conditional variance term and $\mathrm{q}$ on the squared error term. However in general a $\operatorname{GARCH}(1,1)$ model is sufficient. Asymmetric GARCH models due to the leverage effect with asset prices, where a positive shock has less effect on the conditional variance compared to a negative shock.

The leverage effect was first detected with companies share prices. When the share prices are falling they increase the debt

\footnotetext{
${ }^{1}$ Long memory refers to the rate of decay of statistical dependence of two points with increasing time interval or spatial distance between the points.
} 
to equity ratio of firms (Nelson, 1991). Thus, the higher uncertainty of high level, therefore we have a more increasing volatility. EGARCH is given by:

$$
\begin{aligned}
& \varepsilon_{t}=\sigma_{t} z_{t} ; \ln \sigma^{2}=\omega+\alpha_{i} \varepsilon_{t-i}^{2}+ \\
& \sum_{j=1}^{q} \lambda_{j} \ln \left(\sigma_{t-j}^{2}\right)+\sum_{i=1}^{p} y_{i}\left(\frac{\left|\varepsilon_{t-i}\right|}{\sigma_{t-i}}-\sqrt{\frac{2}{\pi}}\right) .
\end{aligned}
$$

\subsubsection{The GJR-GARCH Model}

A major implication of ARCH and GARCH models is that they deal with symmetricity the shocks. Further, the positive effects will have the same effects with the negative effects in volatility. Despite of that, negative shocks in equities market have major implications in volatility than positive shocks of the same magnitude. There is a negative correlation between stock returns and their volatility. According to the impact news curve, volatility tends to rise in response to bad news and to fall following good news. We cannot assume and thus explain the positive or negative unanticipated excess return that characterizes the $\sigma_{t}^{2}$.

GJR-GARCH model for the conditional variance is:

$$
\begin{aligned}
& \zeta_{t}^{2}=\omega+\sum_{i=1}^{p} a_{i} \varepsilon_{t}^{2}+\sum_{j=1}^{q} \beta_{j} \sigma_{t-j}^{2}+\sum_{i=1}^{p} y_{i} I_{t-i} \varepsilon_{t-i}^{2} \\
& I_{t-1}=\left\{1 \text { if } \varepsilon_{t-i}<0 ;\left\{0 \text { if } \varepsilon_{t-1}>-0 .\right.\right.
\end{aligned}
$$

Essentially, this model has an extra parameter to incorporate leverage in the model. The parameter $g$ represents the behavior of volatility to markets shocks (Glosten et al., 1993). If gamma is positive the volatility increases as more negative news are stated than positive shocks ("leverage effect").

\subsubsection{The Integrated GARCH Model}

Financial time series are characterized by long memory and the volatility endures for a long time period. The Integrated GARCH model includes this issue (Bollerslev,1986). It is a special case when $\alpha+\beta=1$. Present volatility influences forecasts of future volatility indefinitely. In this model, the unconditional variance is infinite and there is no critical mean reversion. The researcher should proceed with caution as convergence towards normality of aggregated returns is inconsistent with the IGARCH model. There is also the issue of misspecification of the conditional variance function.

IGARCH resembles a random walk with drifts $\mathrm{m}$. But there are complications with that aspect. A linear random walk is non-stationary in both ways. Firstly, there is no stationary distribution. Secondly, the process is clearly covariance non-stationary. The conditional variance is given by:

$\sigma_{t}^{2}=\omega+\beta_{1} \sigma_{t-1}^{2}+\left(1-\beta_{1}\right) \varepsilon_{t-1}^{2}$

where $1>\beta>0$.

IGARCH is strictly stationary, as the sum of coefficients is restricted to 1 , while stationary distribution is not characterized of unconditional moments. The model has a stationary distribution when $\omega=0$. Et $[\mathrm{s} 2 \mathrm{t}+\mathrm{j}]=\sigma 2 \tau+\mathrm{j} \omega$. When $\omega=0$, then volatility states as a martingale. But martingale states explicitly that a bounded martingale must converge. The volatility cannot be negative therefore it converges to zero. Under the $\operatorname{IGARCH}(1,1)$ the unconditional variance of $y_{t}$ is not defined.

\subsubsection{Forecasting Evaluation}

When the models have been estimated, they are used to proceed with 5-step volatility forecasts. Forecasting volatility with GARCH type models is the conditional variance of the returns at each time period, based on past values, is the same with the conditional variance of the residuals for the same period given its prior values. Forecasting along with the estimations of GARCH models provides a useful way to monitor volatility and find patterns. Forecasts are extracted for the whole of the out of sample period for all five countries. As stated above, the conditional variance equation

$h_{t}=a_{0}+a_{1} u_{t-1}^{2}+\beta h_{t-1}$

Where all variables are known.

The one step- ahead forecast is calculated as $h_{t+1}=a_{0}+$ $\mathrm{a}_{1} \mathrm{u}_{\mathrm{t}}^{2}+\beta \mathrm{h}_{\mathrm{t}}$

The two step-ahead forecast is calculated as $h_{t+2}=a_{0}+$ $\mathrm{a}_{1} \mathrm{u}_{\mathrm{t}+1}^{2}+\beta \mathrm{h}_{\mathrm{t}+1}$

The five step-ahead forecast is calculated as $h_{t+5}=a_{0}+$ $\mathrm{a}_{1} \mathrm{u}_{\mathrm{t}+4}^{2}+\beta \mathrm{h}_{\mathrm{t}+4}$

For forecasting evaluation a set of loss functions are used. These are the Root Mean Squared Error (RMSE), the Mean Squared Error (MSE) the Mean Absolute Error (MAE) defined as:

$$
\begin{aligned}
& \mathrm{MSE}=\frac{1}{T} \Sigma\left(r_{t}^{2}-\sigma_{t}^{2}\right)^{2} \\
& \mathrm{MAE}=\frac{1}{T} \Sigma\left|r_{t}^{2}-\sigma_{t}^{2}\right| \\
& \mathrm{RMSE}=\sqrt{\frac{1}{T} \Sigma\left(r_{t}^{2}-\sigma_{t}^{2}\right)^{2}}
\end{aligned}
$$

RMSE is a classic error measure that gives a high penalty for large forecast errors. MAE is a forecast criterion that gives the same weight to all forecast errors, while MAPE is a percentage error and its value cannot get negative. In terms of analysis, the lower the value of RMSE and MAE is, the more accurate the model is in terms of forecasting. Finally, to see how well each model tracks price changes, the forecasted volatility is compared to the actual volatility.

\section{DATA AND SUMMARY STATISTICS}

We employed datasets include daily stock market returns from the Brazilian IBOVESPA, Russian IMOEX, the Indian Nifty Index, in Shanghai Stock Index and Johannesburg Stock exchange market along with their respected foreign exchanges rates GBPBRL,GBPRUB,GBPINR,GBPCNY,GBPZAR from $13 / 05 / 1999$ to $22 / 11 / 2018$. The selected data includes periods of financial euphoria and distress in the financial markets. The data are downloaded from BLOOMBERG platform.

By examining the summary statistics presented at Table 1, it can be seen that the mean and the median of all the five countries is positive and not significantly different from zero, implying that equity returns increase slightly as time passes. Furthermore, the large difference between the minimum and the maximum values of the returns indicate that large changes in volatility often occur in the BRICS countries. Therefore, it 
seems that there are provided many opportunities for risk taking by the investors.

We observe that the minimum and maximum values are mainly constant and at the same levels for most exchange rates. The mean value for all variables is nearly positive and only on GBP/CNY was negative. Skewness and kurtosis are indifferent of zero, indicating that they are behaving as time series. Therefore, none has a bell-shape, they don't follow a normal Gaussian distribution. It can also be stated that there exists a leptokurtosis in the distribution, showing that the time series have not accomplished stationarity.

From Table 1 the time series have all the proper characteristics of the financial time series. We detect high kurtosis in all assets and the skewness regarding stock exchanges is lower than zero, while on forex rates it is higher than zero except for the GBPCNY, which is on a negative level. The median and the mean are nearly zero, while the difference between minimum and maximum value declare the high volatility in the BRICS indices. Lastly, the mean and the standard deviation values are close to zero.

\section{EMPIRICAL RESULTS}

This section shows the empirical results for the models that are estimated and their practical impact in volatility in financial markets. The presence of conditional heteroscedasticity in the residuals is after running each model. The tests are presented detailed in Appendix. In all the time series there is $\mathrm{ARCH}$ effects in the residuals, thus the volatility clustering is verified.

Tables 2-11 illustrate the coefficient estimates along with forecasting evaluation measures and the diagnostic test. We run a comparison of models for each asset return to examine which model runs smoothly for each asset. We find the GJRGARCH model includes with success the asymmetric effect in the financial markets. The standardized GARCH is also a very good model in estimating volatility. The SV model provides a more realistic and conservative measure of volatility.

The results (see Tables $\mathbf{2 - 1 1}$ ), provide evidence that the value of the mean coefficient in all models is not statistically significant, while the coefficients a ,b, g, $\omega$ are considered as statistically significant. The $g$ being positive means that negative news will lead to higher conditional variance. By having negative information criteria, we choose the model with lowest negative value on them or according to loglikelihood. Regarding the first we could use the GJR-GARCH, while for the latter we might use the Standardized GARCH model or the GJR model. The gamma is detected as negative in the GJR model for BRICS. In other words it directs that negative shocks affect severely the conditional variance in comparison to positive shocks. The persistence parameter in the EGARCH model is very high proving that volatility decays at a slower pace.

The GARCH (1.1) and IGARCH, the mu coefficient is statistically insignificant while the rest of the coefficients as they present lower p-value than $5 \%$ they are statistically significant. In that way, the IGARCH captures the volatility persistence $a s a+b=1$. The EGARCH depict coefficients of 0 declaring the statistically significance. The same also happens with the GJR but with a mu coefficient not statistically significant. Regarding, JALSH index the EGARCH and the GJR-GARCH shows statistically significance in their coefficients showing that these are the best in capturing volatility in the particular asset return. In GBPRUB the omega coefficient and the mu coefficient of the GARCH(1,1) is statistically significant. After a thorough examination of all diagnostics it can be concluded that the GJR- GARCH model outperforms the others. The standardized GARCH model seems a good choice on modeling volatility. Last but not least, in all model there are $\mathrm{AIC}$ and BIC with negative values. This is irrelevant, as we choose the model with the lower price.

\subsection{Forecasting Evaluation}

We forecasting volatility and after that we try to measure their efficiency. The tables 2-11 include the evaluation estimates that were used for forecasting volatility $(\sigma)$, while there are also included the evaluation measures (MSE,RMSE,MAE). Each table presents the volatility performance, along with the fitted volatility, while state that GJR-GARCH has the highest volatility forecasting power, followed by the SV model, where the volatility reverts successfully to the mean value, outlining that the model fits very well on modeling volatility.

With a 5-step forecasting, the performance of the volatility stabilizes, while the fitted volatility is in some cases negative. In all models GJR-GARCH generates the lowest value for volatility along with the lowest values of MSE, RMSE, and MAE. On the other hand, on the SSE Index, we see that the GARCH(1.1) outperform the others, declaring the efficiency of the model.

\section{CONCLUSIONS}

This working paper uses daily returns of stock indices and foreign exchange rates to estimate and forecast volatility in BRICS. The analysis of the descriptive statistics verifies the definition of financial time series. In each time series for the two variables non-normality, skewness, leptokurtosis, leverage effect and ARCH effects are displayed. The statistical tests show that the financial assets that we study, deviate from normality and exhibit clustering.

GARCH(1,1), IGARCH, GJR-GARCH and EGARCH have been used to model and forecast volatility. The standard GARCH $(1,1)$ is enough in explaining the conditional variance. The GJR-GARCH outperform the other models in estimating volatility except for the index of South Africa, where the EGARCH is superior. Our findings also provide evidence that a nonlinear structure in the conditional variance exists and it can be simulated by using a GARCH $(1,1)$ model. The results suggest that the GJR-GARCH model outperforms the other GARCH-family models and provides a clear direction on how to critically estimate volatility and infer conclusions.

The in sample evidence indicates that forex and stock returns' volatility is characterized by significant persistence and asymmetric effects. It also observable the volatility spillover and the time-varying correlations.

\section{CONFLICT OF INTEREST STATEMENT}

The authors declare that they have no conflict of interest. 


\section{APPENDIX}

Table 1. Descriptive Statistics of the Asset Log Returns in BRICS.

\begin{tabular}{|c|c|c|c|c|c|c|c|}
\hline & Mean & SD & Min & Max & Skew & Kurt & Nobs \\
\hline GBPBRL & 0.00005 & 0.004 & -0.044 & 0.030 & 0.043 & 5.372 & 5096 \\
\hline GBPRUB & 0.00006 & 0.003 & -0.044 & 0.048 & 0.570 & 20.59 & 5096 \\
\hline GBPINR & 0.00002 & 0.002 & -0.031 & 0.015 & 0.538 & 6.334 & 5096 \\
\hline GBPCNY & -0.00003 & 0.002 & -0.032 & 0.017 & -0.554 & 8.604 & 5096 \\
\hline GBPZAR & 0.00004 & 0.004 & -0.057 & 0.062 & 0.430 & 14.993 & 5096 \\
\hline IBOVESPA & 0.00016 & 0.007 & -0.052 & 0.059 & -0.105 & 4.113 & 5096 \\
\hline IMOEX & 0.00027 & 0.008 & -0.089 & 0.109 & -0.110 & 14.652 & 5096 \\
\hline NIFTY & 0.00018 & 0.006 & -0.056 & 0.070 & -0.247 & 9.331 & 5096 \\
\hline SHCOMP & 0.00007 & 0.006 & -0.040 & 0.040 & -0.309 & 5.261 & 5096 \\
\hline JALSH & 0.00017 & 0.005 & -0.034 & 0.029 & -0.165 & 3.844 & 5096 \\
\hline
\end{tabular}

Table 2. Estimation Results and Forecasting Evaluation Measures for GBPBRL.

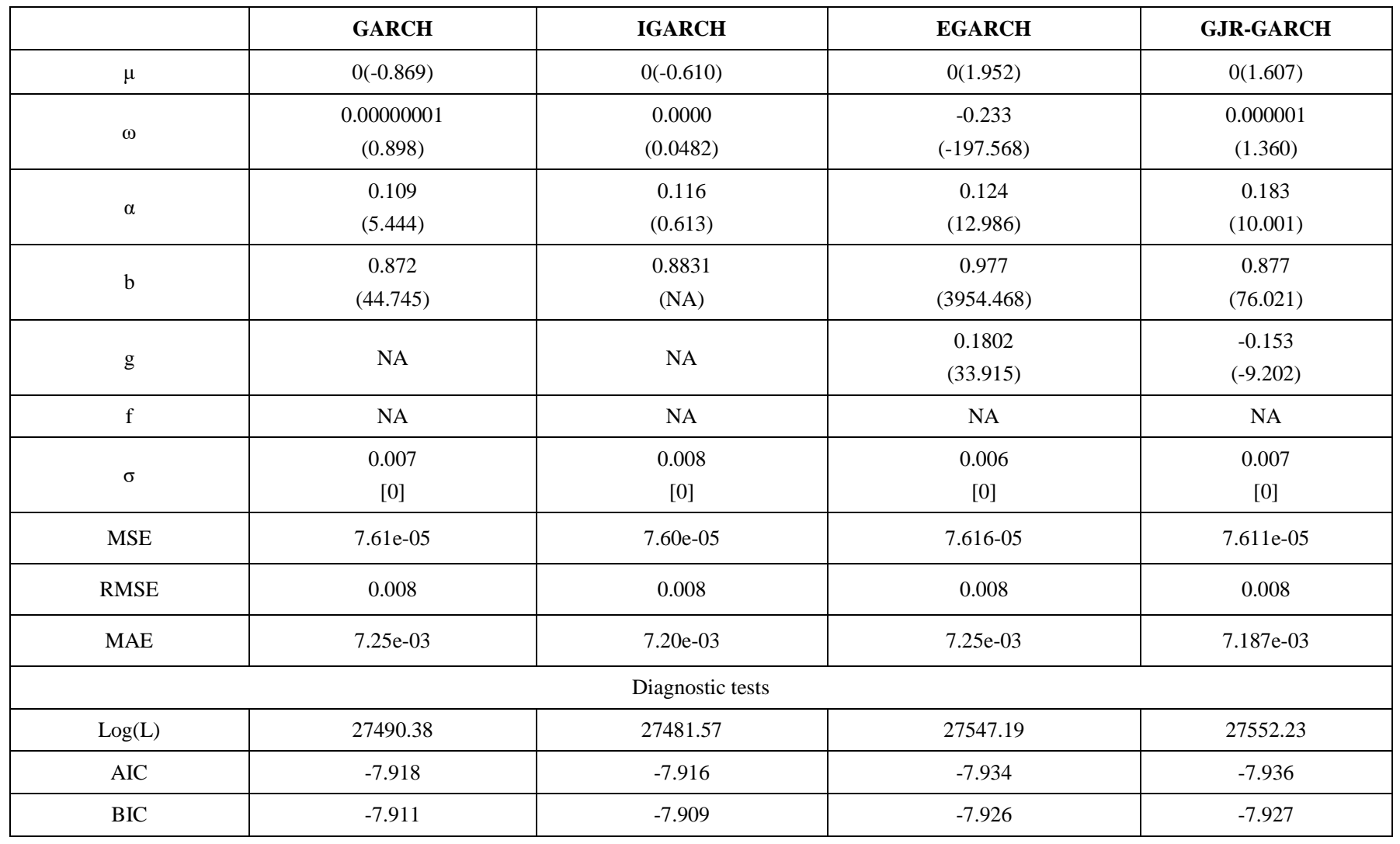

Note: Values in the parenthesis are the t- statistic. Values in the brackets are the fitted values for volatility.

Table 3. Estimation Result and Forecasting Evaluation Measures for GBPRUB.

\begin{tabular}{|c|c|c|c|c|}
\hline & GARCH & IGARCH & EGARCH & GJR-ARCH \\
\hline$\mu$ & 0.00008 & 0.0003 & 0.0012 & 0.00001 \\
$(0.185)$ & $(0.131)$ & $(6.331)$ & $-067)$ \\
\hline$\omega$ & 0 & 0 & $(-174.125)$ & 0 \\
& $(0)$ & $(0.142)$ & 0.062 & $(0.143)$ \\
$\alpha$ & 0.063 & 0.025 & $(5.284)$ & $(31.619)$ \\
\hline
\end{tabular}




\begin{tabular}{|c|c|c|c|c|}
\hline $\mathrm{b}$ & $\begin{array}{c}0.931 \\
(2733.235)\end{array}$ & $\begin{array}{l}0.974 \\
\text { (NA) }\end{array}$ & $\begin{array}{c}0.906 \\
(1581.512)\end{array}$ & $\begin{array}{c}0.9 \\
(3337.186)\end{array}$ \\
\hline $\mathrm{g}$ & NA & NA & $\begin{array}{c}0.225 \\
(26.252)\end{array}$ & $\begin{array}{c}0.05 \\
(12.602)\end{array}$ \\
\hline$\varphi$ & NA & NA & NA & NA \\
\hline$\sigma$ & $\begin{array}{c}0.002175 \\
{[1.018 \mathrm{e}-05]}\end{array}$ & $\begin{array}{c}0.002 \\
{[9.541-06]}\end{array}$ & $\begin{array}{c}0.003 \\
{[1.297 \mathrm{e}-04]}\end{array}$ & $\begin{array}{c}0.001 \\
{[6.980 \mathrm{e}-06]}\end{array}$ \\
\hline $\begin{array}{c}\text { MSE } \\
\text { RMSE } \\
\text { MAE }\end{array}$ & $\begin{array}{c}7.616 \mathrm{e}-05 \\
0.008 \\
7.253 \mathrm{e}-03\end{array}$ & $\begin{array}{c}7.605 \mathrm{e}-05 \\
0.008 \\
7.208 \mathrm{e}-03\end{array}$ & $\begin{array}{c}7.616 \mathrm{e}-05 \\
0.008 \\
7.251 \mathrm{e}-03\end{array}$ & $\begin{array}{l}0.007 \\
0.008 \\
0.007\end{array}$ \\
\hline \multicolumn{5}{|c|}{ Diagnostic tests } \\
\hline $\log (\mathrm{L})$ & 29604.65 & 29759.99 & 29631.92 & 29218.57 \\
\hline AIC & -8.528 & -8.574 & -8.536 & -8.417 \\
\hline $\mathrm{BIC}$ & -8.524 & -8.570 & -8.530 & -8.411 \\
\hline
\end{tabular}

Note: Values in the parenthesis are the t- statistic. Values in the brackets are the fitted values for volatility.

Table 4. Estimation Results and Forecasting Evaluation Measures for GBPINR.

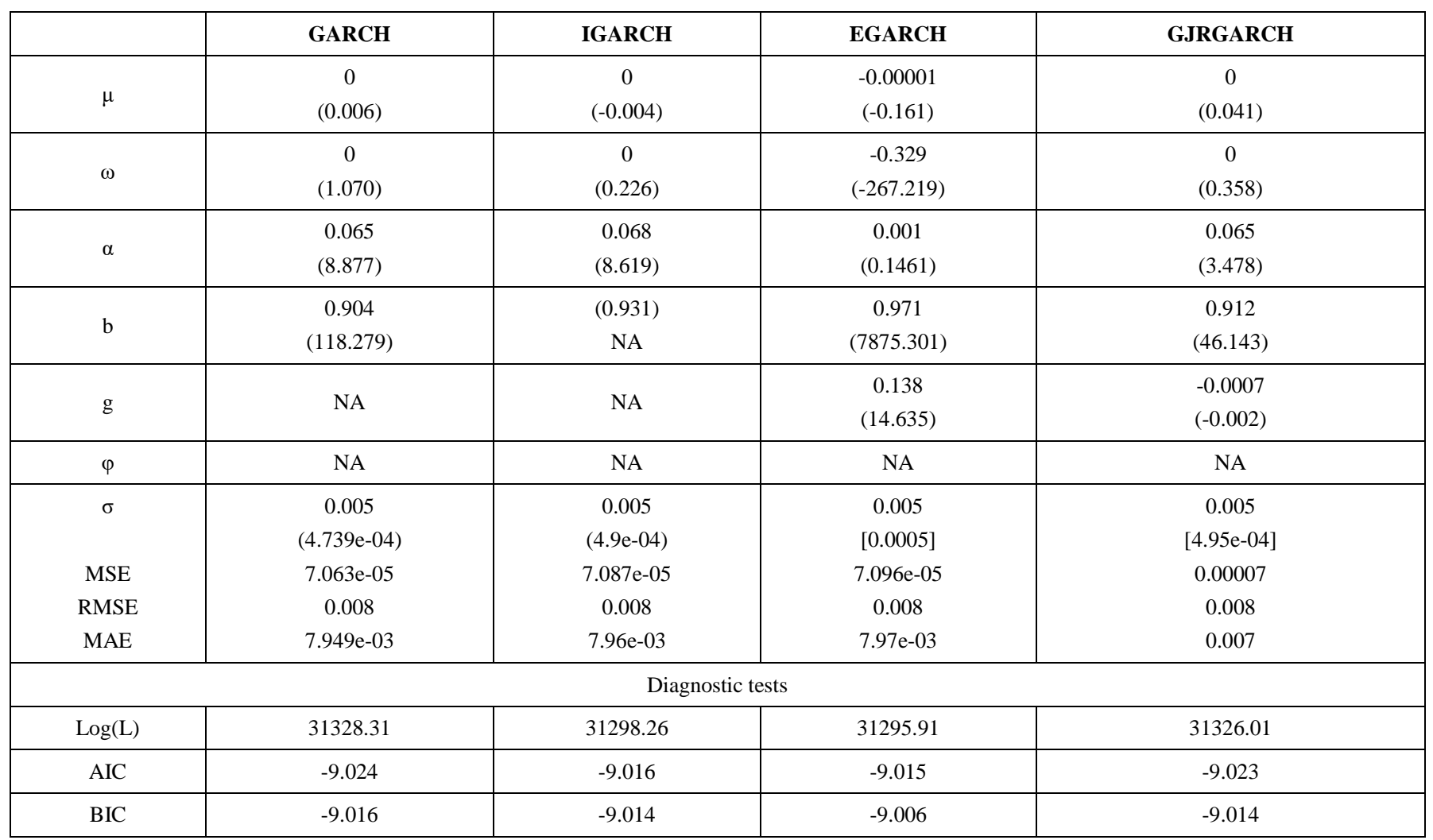

Note: Values in the parenthesis are the t- statistic. Values in the brackets are the fitted values for volatility.

Table 5. Estimation Results and Forecasting Evaluation Measures for GBPCNY.

\begin{tabular}{|c|c|c|c|c|}
\hline & GARCH & IGARCH & EGARCH \\
\hline$\mu$ & 0.0004 & -0.0003 & -0.00005 \\
$(-0.066)$ & -0.000002 \\
$(-0.285)$ & -0.084 & $(-4.405)$ \\
\hline$\omega$ & $0.063)$ & 0.0004 & $(0.504)$ \\
\hline$\alpha$ & $(5.996)$ & $(5.406)$ & 0.0124 \\
$(10.082)$ & $(10.258)$ & $(1.227)$ \\
\hline
\end{tabular}




\begin{tabular}{|c|c|c|c|c|}
\hline$\beta$ & $\begin{array}{c}0.904 \\
(89.824) \\
\end{array}$ & $\begin{array}{l}0.928 \\
\text { (NA) }\end{array}$ & $\begin{array}{c}0.967 \\
(139.078) \\
\end{array}$ & $\begin{array}{c}0.916 \\
(75.606) \\
\end{array}$ \\
\hline $\mathrm{g}$ & NA & NA & $\begin{array}{c}0.137 \\
(8.930)\end{array}$ & $\begin{array}{c}0.001 \\
(0.123)\end{array}$ \\
\hline$\varphi$ & NA & NA & NA & NA \\
\hline$\sigma$ & $\begin{array}{c}0.267 \\
(-0.008)\end{array}$ & $\begin{array}{c}0.292 \\
(-0.008)\end{array}$ & $\begin{array}{c}0.278 \\
(-0.007]\end{array}$ & $\begin{array}{c}0.002 \\
{[-0.0006]}\end{array}$ \\
\hline MSE & 0.0006 & 0.0006 & $6.896 \mathrm{e}-05$ & $6.93 \mathrm{e}-05$ \\
\hline RMSE & 0.008 & 0.008 & 0.008 & 0.008 \\
\hline MAE & 0.006 & 0.006 & $6.962 \mathrm{e}-03$ & $6.974 \mathrm{e}-03$ \\
\hline \multicolumn{5}{|c|}{ Diagnostic tests } \\
\hline BIC & 0.028 & 0.036 & 0.039 & -9.186 \\
\hline
\end{tabular}

Note: Values in the parenthesis are the t- statistic. Values in the brackets are the fitted values for volatility.

Table 6. Estimation Results and Forecasting Evaluation Measures GBPZAR.

\begin{tabular}{|c|c|c|c|c|}
\hline & GARCH & IGARCH & EGARCH & GJR GARCH \\
\hline$\mu$ & $\begin{array}{l}0.0003 \\
(0.252)\end{array}$ & $\begin{array}{l}0.0002 \\
(0.199)\end{array}$ & $\begin{array}{c}0.002 \\
(2.340)\end{array}$ & $\begin{array}{c}0.002 \\
(1.842)\end{array}$ \\
\hline$\alpha$ & $\begin{array}{c}0.099 \\
(12.458)\end{array}$ & $\begin{array}{c}0.104 \\
(12.548)\end{array}$ & $\begin{array}{c}0.113 \\
(10.585)\end{array}$ & $\begin{array}{c}0.135 \\
(12.184)\end{array}$ \\
\hline$\gamma$ & NA & NA & $\begin{array}{c}0.137 \\
(10.223)\end{array}$ & $\begin{array}{c}-0.130 \\
(-10.038)\end{array}$ \\
\hline$\varphi$ & NA & NA & NA & NA \\
\hline RMSE & 0.012 & 0.012 & 0.012 & 0.012 \\
\hline MAE & 0.010 & 0.010 & 0.010 & 0.010 \\
\hline \multicolumn{5}{|c|}{ Diagnostic tests } \\
\hline $\log (\mathrm{L})$ & -4169.024 & -4182.135 & -4136.113 & -4118.977 \\
\hline AIC & 1.203 & 1.207 & 1.194 & 1.189 \\
\hline BIC & 1.212 & 1.215 & 1.204 & 1.199 \\
\hline
\end{tabular}

Note: Values in the parenthesis are the t- statistic. Values in the brackets are the fitted values for volatility.

Table 7. Estimation Results and Forecasting Evaluation Measures for IBOVESPA.

\begin{tabular}{|c|c|c|c|c|}
\hline & GARCH & IGARCH & EGARCH & GJRGARCH \\
\hline \multirow{3}{*}{$\mu$} & 0.00002 & 0.000002 & -0.00002 & -0.00002 \\
& $(0.029)$ & $(0.031)$ & $(-0.023)$ & $(-0.059)$ \\
\hline
\end{tabular}




\begin{tabular}{|c|c|c|c|c|}
\hline$\omega$ & $\begin{array}{l}0.0003 \\
(0.964)\end{array}$ & $\begin{array}{c}0.00001 \\
(1.800)\end{array}$ & $\begin{array}{c}-0.208 \\
(-42.817)\end{array}$ & $\begin{array}{c}0.000003 \\
(2.961)\end{array}$ \\
\hline$\alpha$ & $\begin{array}{c}0.110 \\
(11.069)\end{array}$ & $\begin{array}{c}0.119 \\
(9.230)\end{array}$ & $\begin{array}{c}-0.137 \\
(-8.957)\end{array}$ & $\begin{array}{c}0.022 \\
(2.407)\end{array}$ \\
\hline b & $\begin{array}{c}0.850 \\
(33.732)\end{array}$ & $\begin{array}{l}0.880 \\
\text { (NA) }\end{array}$ & $\begin{array}{c}0.978 \\
(655.705)\end{array}$ & $\begin{array}{c}0.867 \\
(72.100)\end{array}$ \\
\hline $\mathrm{g}$ & NA & NA & NA & $\begin{array}{c}0.169 \\
(8.352)\end{array}$ \\
\hline$\varphi$ & NA & NA & NA & NA \\
\hline$\sigma$ & $\begin{array}{c}0.011 \\
{[0.0001]}\end{array}$ & $\begin{array}{c}0.011 \\
{[0.001]}\end{array}$ & $\begin{array}{l}0.0115 \\
{[0.000]}\end{array}$ & $\begin{array}{c}0.009 \\
{[0.001]}\end{array}$ \\
\hline MSE & 0.0003 & 0.0003 & 0.0003 & 0.0003 \\
\hline RMSE & 0.005 & 0.012 & 0.012 & 0.012 \\
\hline MAE & 0.017 & 0.017 & 0.017 & 0.017 \\
\hline \multicolumn{5}{|c|}{ Diagnostic tests } \\
\hline $\log (\mathrm{L})$ & 23128.81 & 23103.39 & 23151.87 & 23183.05 \\
\hline AIC & -6.663 & -6.655 & -6.669 & -6.678 \\
\hline $\mathrm{BIC}$ & -6.658 & -6.652 & -6.663 & -6.672 \\
\hline
\end{tabular}

Note: Values in the parenthesis are the t- statistic. Values in the brackets are the fitted values for volatility.

Table 8. Estimation Results and Forecasting Evaluation Measures for IMOEX.

\begin{tabular}{|c|c|c|c|c|}
\hline & GARCH & IGARCH & EGARCH & GJR GARCH \\
\hline$\mu$ & $\begin{array}{c}0.00002 \\
(0.417)\end{array}$ & $\begin{array}{c}0.00003 \\
(0.511)\end{array}$ & $\begin{array}{l}-0.0001 \\
(-2.587)\end{array}$ & $\begin{array}{l}-0.0001 \\
(-2.445)\end{array}$ \\
\hline$\omega$ & $\begin{array}{c}0.00002 \\
(2.198)\end{array}$ & $\begin{array}{c}0.000001 \\
(1.771)\end{array}$ & $\begin{array}{c}-0.197 \\
(-27.817)\end{array}$ & $\begin{array}{l}0.00002 \\
(2.208)\end{array}$ \\
\hline$\alpha$ & $\begin{array}{c}0.118 \\
(9.994)\end{array}$ & $\begin{array}{c}0.126 \\
(10.147)\end{array}$ & $\begin{array}{c}-0.095 \\
(-7.315)\end{array}$ & $\begin{array}{c}0.057 \\
(4.988)\end{array}$ \\
\hline $\mathrm{b}$ & $\begin{array}{c}0.870 \\
(70.727)\end{array}$ & $\begin{array}{l}0.873 \\
(\mathrm{NA})\end{array}$ & $\begin{array}{c}0.978 \\
(1230.723)\end{array}$ & $\begin{array}{c}0.109 \\
(6.529)\end{array}$ \\
\hline $\mathrm{g}$ & NA & NA & $\begin{array}{c}0.194 \\
(18.012)\end{array}$ & $\begin{array}{c}0.109 \\
(2.058)\end{array}$ \\
\hline$\varphi$ & NA & NA & NA & NA \\
\hline$\sigma$ & $\begin{array}{c}0.022 \\
{[-0.001]}\end{array}$ & $\begin{array}{c}0.023 \\
{[-0.001]}\end{array}$ & $\begin{array}{c}0.019 \\
{[-0.001]}\end{array}$ & $\begin{array}{c}0.022 \\
{[-0.001]}\end{array}$ \\
\hline MSE & 0.0001 & 0.0001 & $9.57 \mathrm{e}-05$ & $9.59 \mathrm{e}-05$ \\
\hline RMSE & 0.010 & 0.010 & 0.009 & 0.009 \\
\hline MAE & 0.009 & 0.009 & $9.62 \mathrm{e}-03$ & $9.62 \mathrm{e}-03$ \\
\hline \multicolumn{5}{|c|}{ Diagnostic tests } \\
\hline $\log (\mathrm{L})$ & 22751.95 & 22747.43 & 22722.83 & 22773.54 \\
\hline $\mathrm{AIC}$ & -6.554 & -6.553 & -6.545 & -6.560 \\
\hline $\mathrm{BIC}$ & -5.549 & -6.549 & -6.539 & -6.554 \\
\hline
\end{tabular}

Note: Values in the parenthesis are the t- statistic. Values in the brackets are the fitted values for volatility. 
Table 9. Estimation Results and Forecasting Evaluation Measures for NIFTY INDEX.

\begin{tabular}{|c|c|c|c|c|}
\hline & GARCH & IGARCH & EGARH & GJRGARCH \\
\hline$\mu$ & $\begin{array}{l}0.00006 \\
(1.609)\end{array}$ & $\begin{array}{l}0.0006 \\
(1.663)\end{array}$ & $\begin{array}{l}-0.0002 \\
(-5.092)\end{array}$ & $\begin{array}{l}-0.0001 \\
(-3.777)\end{array}$ \\
\hline$\omega$ & $\begin{array}{c}0.000001 \\
(2.474)\end{array}$ & $\begin{array}{c}0.000001 \\
(1.879)\end{array}$ & $\begin{array}{c}-0.252 \\
(-10.400)\end{array}$ & $\begin{array}{c}0.000001 \\
(2.390)\end{array}$ \\
\hline$\alpha$ & $\begin{array}{c}0.164 \\
(11.710)\end{array}$ & $\begin{array}{c}0.175 \\
(12.988)\end{array}$ & $\begin{array}{c}-0.190 \\
(-13.911)\end{array}$ & $\begin{array}{c}0.048 \\
(4.774)\end{array}$ \\
\hline $\mathrm{b}$ & $\begin{array}{c}0.822 \\
(63.125)\end{array}$ & $\begin{array}{l}0.824 \\
\text { (NA) }\end{array}$ & $\begin{array}{c}0.974 \\
(396.329)\end{array}$ & $\begin{array}{c}0.834 \\
(72.762)\end{array}$ \\
\hline $\mathrm{g}$ & NA & NA & $\begin{array}{c}0.2478 \\
(16.017)\end{array}$ & $\begin{array}{c}0.231 \\
(10.487)\end{array}$ \\
\hline$\varphi$ & NA & NA & NA & NA \\
\hline$\sigma$ & $\begin{array}{c}0.020 \\
{[-0.0008]}\end{array}$ & $\begin{array}{c}0.021 \\
{[-0.0008]}\end{array}$ & $\begin{array}{c}0.013 \\
{[-0.001]}\end{array}$ & $\begin{array}{c}0.015 \\
{[-0.001]}\end{array}$ \\
\hline MSE & $3.445 \mathrm{e}-05$ & 0.00003 & 0.00003 & 0.00003 \\
\hline RMSE & 0.005 & 0.005 & 0.005 & 0.005 \\
\hline MAE & $4.963868 \mathrm{e}-03$ & 0.004 & 0.004 & $4.920 \mathrm{e}-03$ \\
\hline \multicolumn{5}{|c|}{ Diagnostic tests } \\
\hline $\log (\mathrm{L})$ & 25160.71 & 25157.74 & 25257.06 & 25234.91 \\
\hline AIC & -7.248 & -7.247 & -7.275 & -7.269 \\
\hline BIC & -7.243 & -7.243 & -7.270 & -7.263 \\
\hline
\end{tabular}

Note: Values in the parenthesis are the t- statistic. Values in the brackets are the fitted values for volatility.

Table 10. Estimation Results and Forecasting Evaluation Measures for SSE.

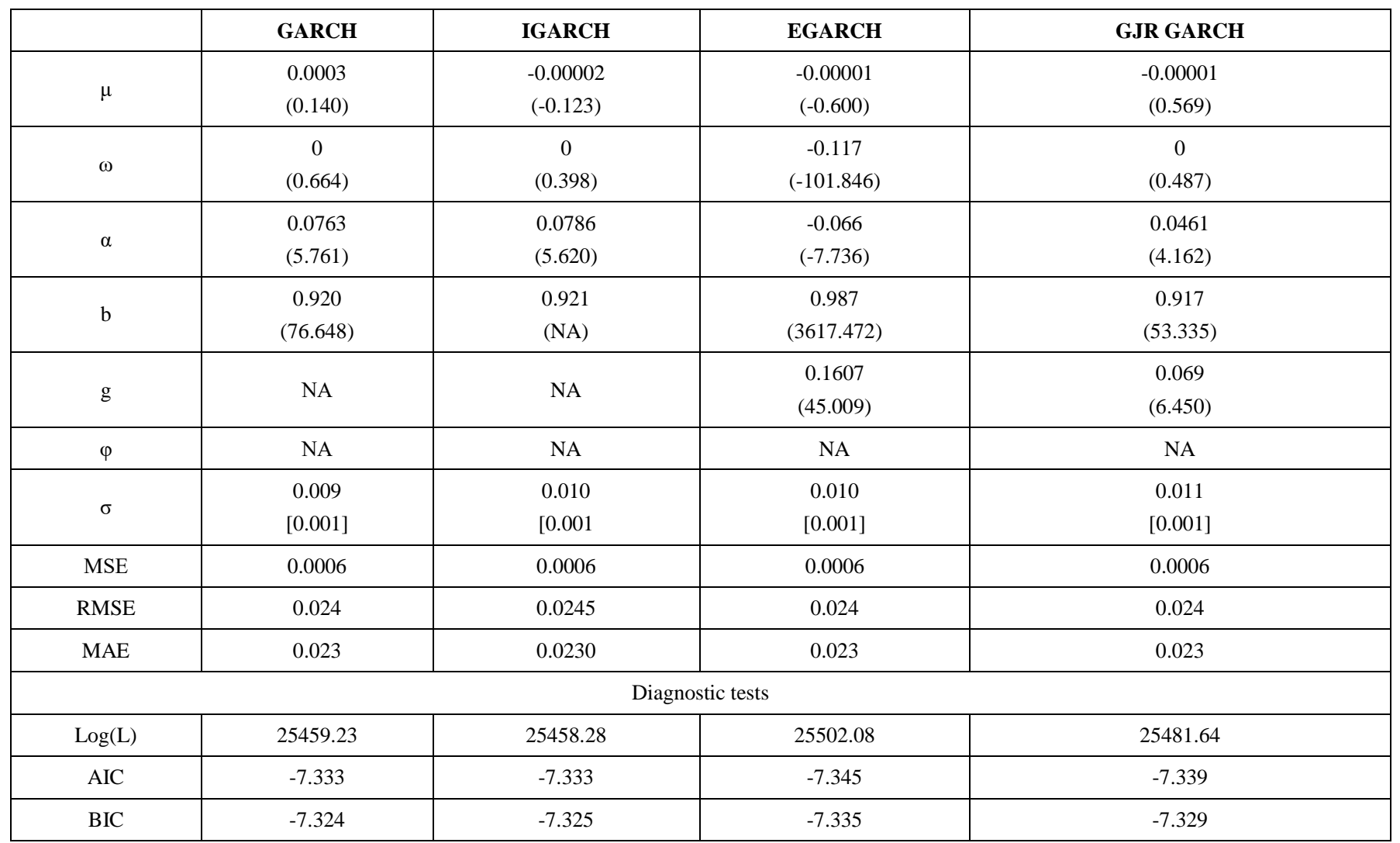


Table 11. Estimating Results and Forecast Evaluation Measures for JALSH INDEX.

\begin{tabular}{|c|c|c|c|c|}
\hline & GARCH & IGARCH & EGARCH & GJR GARCH \\
\hline$\mu$ & $\begin{array}{l}0.0001 \\
(0.443)\end{array}$ & $\begin{array}{c}0.00001 \\
(0.420)\end{array}$ & $\begin{array}{l}-0.0001 \\
(-3.158)\end{array}$ & $\begin{array}{c}-0.010 \\
(-2.466)\end{array}$ \\
\hline$\omega$ & $\begin{array}{c}0.00001 \\
(0.751)\end{array}$ & $\begin{array}{c}0 \\
(0.285)\end{array}$ & $\begin{array}{c}-0.218 \\
(-10.595)\end{array}$ & $\begin{array}{c}0.006 \\
(5.721)\end{array}$ \\
\hline$\alpha$ & $\begin{array}{c}0.112 \\
(4.156)\end{array}$ & $\begin{array}{c}0.121 \\
(3.089)\end{array}$ & $\begin{array}{c}-0.094 \\
(-6.701)\end{array}$ & $\begin{array}{c}0.057 \\
(5.765)\end{array}$ \\
\hline $\mathrm{b}$ & $\begin{array}{c}0.871 \\
(32.961) \\
\end{array}$ & $\begin{array}{l}0.878 \\
\text { (NA) } \\
\end{array}$ & $\begin{array}{c}0.978 \\
(495.045) \\
\end{array}$ & $\begin{array}{c}0.877 \\
(97.131) \\
\end{array}$ \\
\hline g & NA & NA & $\begin{array}{c}0.207 \\
(16.128)\end{array}$ & $\begin{array}{c}0.107 \\
(4.506)\end{array}$ \\
\hline$\varphi$ & NA & NA & NA & NA \\
\hline$\sigma$ & $\begin{array}{c}0.016 \\
{[-0.001]}\end{array}$ & $\begin{array}{c}0.018 \\
{[-0.001]}\end{array}$ & $\begin{array}{c}0.012 \\
{[-0.001]}\end{array}$ & $\begin{array}{c}1.519 \\
{[0.143]}\end{array}$ \\
\hline MSE & 0.0001 & 0.0001 & 0.0001 & 0.0001 \\
\hline RMSE & 0.012 & 0.012 & 0.011 & 0.0119 \\
\hline MAE & 0.011 & 0.011 & 0.0112 & 0.0112 \\
\hline \multicolumn{5}{|c|}{ Diagnostic tests } \\
\hline $\log (\mathrm{L})$ & 26387.69 & 26381.32 & 26396.1 & -5556.949 \\
\hline AIC & -7.602 & -7.600 & -7.604 & 1.602 \\
\hline BIC & -7.597 & -7.596 & -7.598 & 1.608 \\
\hline
\end{tabular}

Note: Values in the parenthesis are the t- statistic. Values in the brackets are the fitted values for volatility.

\section{REFERENCES}

Alberg, D., Shalit, H. and Yosef, R. (2008). "Estimating stock market volatility using asymmetric GARCH models". Applied Financial Economics, 18(15), pp.1201-1208.

Chang, C. and McAleer, M. (2017). "The correct regularity condition and interpretation of asymmetry in EGARCH". Economics Letters, 161, pp.52-55.

Choudhry, T. and Wu, H. (2008). "Forecasting ability of GARCH vs Kalman filter method: evidence from daily UK time-varying beta". Journal of Forecasting, 27(8), pp.670-689.

Degiannakis, S. and Xekalaki, E. (1999). "Predictability and Model Selection in the Context of Arch Model"s. SSRN Electronic Journal.

Dritsaki, C. (2018). "Modeling and Forecasting of British Pound/US Dollar Exchange Rate: An Empirical Analysis". Advances in Panel Data Analysis in Applied Economic Research, pp.437-455.

Gao, H., Li, J., Guo, W. and Mei, D. (2018). "The synchronicity between the stock and the stock index via information in marke"t. Physica A: Statistical Mechanics and its Applications, 492, pp.1382-1388.

Gong, X., He, Z., Li, P. and Zhu, N. (2014). "Forecasting Return Volatility of the CSI 300 Index Using the Stochastic Volatility Model with Continuous Volatility and Jumps." Discrete Dynamics in Nature and Society, 2014, pp.1-10.

Gujarati, D. (2015). Econometrics by example. London: Palgrave.

Hafner, C. and Preminger, A. (2010). "Deciding between GARCH and stochastic volatility via strong decision rules". Journal of Statistical Planning and Inference, 140(3), pp.791-805.

Hardiyanto, A. (2007). "Daily Rp/USD stochastic volatility and the policy implication lesson". Journal of Asian Economics, 18(1), pp.237-256.

Kishor, N. and Singh, R. (2014). "Stock Return Volatility Effect: Study of BRICS”. Transnational Corporations Review, 6(4), pp.406-418.
Lin, Z. (2018). "Modelling and forecasting the stock market volatility of SSE Composite Index using GARCH models". Future Generation Computer Systems, 79, pp.960-972.

Liu, H. and Hung, J. (2010). 'Forecasting S\&P-100 stock index volatility: The role of volatility asymmetry and distributional assumption in GARCH models'. Expert Systems with Applications, 37(7), pp.4928-4934.

Mariani, M., Bhuiyan, M., Tweneboah, O., Gonzalez-Huizar, H. and Florescu, I. (2018). "Volatility models applied to geophysics and high frequency financial market data". Physica A: Statistical Mechanics and its Applications, 503, pp.304-321.

Merton, R., 1973. Theory of Rational Option Pricing. The Bell Journal of Economics and Management Science, 4(1), p.141.

Nelson, D. (1991). "Conditional Heteroskedasticity in Asset Returns: A New Approach". Econometrica, 59(2), p.347.

Pelinescu, E. (2014). "Volatility Analysis of the Romanian Exchange Rate". Procedia Economics and Finance, 8, pp.543-549.

Sharma, P. and Vipul (2016). "Forecasting stock market volatility using Realized GARCH model: International evidence". The Quarterly Review of Economics and Finance, 59, pp.222-230.

So, M. and Yu, P. (2006). "Empirical analysis of GARCH models in value at risk estimation". Journal of International Financial Markets, Institutions and Money, 16(2), pp.180-197.

Tsay, R (2010). “Analysis of Financial Time Series". 3rd ed. Chicago: Wiley Finance. p1-673.

Waqas, Y., Hashmi, S. and Nazir, M. (2015). "Macroeconomic factors and foreign portfolio investment volatility: A case of South Asian countries". Future Business Journal, 1(1-2), pp.65-74. 